\title{
A genômica funcional no âmbito da produção animal: estado da arte e perspectivas
}

\author{
Luiz Roberto Furlan', André Luiz Julien Ferraz², Julio César Bortolossi²
}

1 - Departamento de Melhoramento e Nutrição Animal, Faculdade de Medicina Veterinária e Zootecnia/FMVZ, UNESP, Botucatu, Brasil.E-mail: cedral@fca.unesp.br.

2 - Departamento de Tecnologia, Faculdade de Ciências Agrárias e Veterinárias/FCAV, UNESP, Jaboticabal, Brasil.

RESUMO - Os últimos vinte anos caracterizaram-se pela proliferação de tecnologias que tornaram possível decifrar o genoma das espécies, localizar e identificar particularidades na sua seqüência, elucidar as suas funções dentro dos sistemas biológicos e, sobretudo, começar a entender os mecanismos que controlam as interações entre os genótipos e os estímulos ambientais, que são responsáveis pela diversidade fenotípica. Estes estudos sobre as bases moleculares da variabilidade fenotípica abriram uma nova abordagem científica, caracterizada pela multiplicidade das questões envolvidas, que resultou no surgimento de novas áreas de pesquisa, cujos conhecimentos estão sendo aplicados em diversos campos da biologia, inclusive na zootecnia. Tendo em vista o grande impacto que tais conhecimentos estão tendo sobre a compreensão dos fenômenos biológicos, parece ser oportuno fazer uma avaliação das potencialidades de aplicação das abordagens de Genômica Funcional em pesquisas de nutrição e alimentação de ruminantes. Nesse contexto, este artigo está focado na descrição das principais "ferramentas genômicas" disponíveis e na discussão sobre a viabilidade de se utilizar as informações por elas geradas em benefício da produção animal.

Palavras-chave: bovinos, expressão gênica, genômica funcional, microarrays, nutrição, polimorfismo

\section{Functional genomics in the field of animal science: state-of-the-art and perspectives}

\footnotetext{
ABSTRACT - The last twenty years have been characterized by some remarkable technological advances in the field of genomics which were essential to unveil the genome of varies species. Furthermore, these genomic advances contributed to pinpoint particularities in genome sequences which might be associated with phenotypic variations, therefore, it became possible to study functions associated with specific sequences in a more holistic context within biological systems. More importantly, the blossoming in genomics contributed to a better understanding on the mechanisms that control the interactions between genotype and environmental factors which are responsible for phenotypic variability. Genomic advances also promoted innovative and multi-dimensional scientific perspectives in research fields of biology, such as in animal science. Having in mind the remarkable impacts of genomics on the understanding of biological phenomena, it becomes clear that an assessment of the potential applications of functional genomics in the field ruminant nutrition should be performed. For this reason, this paper reviews several important genomic tools, and discusses the feasibility of using these tools towards an enhancement of animal production.
}

Key Words: bovine, functional genomics, gene expression, microarrays, nutrition, polymorphism

\section{Introdução}

Os conhecimentos sobre a natureza e conteúdo da informação genética, assim como as tecnologias disponíveis para o seqüenciamento de genomas em larga escala, evoluíram de uma forma sem precedentes nas duas últimas décadas, permitindo que os bancos de dados públicos acumulassem um enorme volume de informações acerca das sequiências de nucleotídeos de diversos genomas, dentre os quais o dos bovinos e de outros animais de interesse zootécnico. 
Contudo, os dados obtidos nos projetos de seqüenciamento não têm contribuído da forma esperada para o melhor entendimento do papel que os genes e as proteínas desempenham no funcionamento dos organismos, uma vez que o genoma é um elemento virtualmente estático, ao passo que seus produtos, representados pelos RNAs mensageiros (transcriptoma) e proteínas (proteoma), possuem um caráter dinâmico, caracterizado por mudanças contínuas em resposta à estímulos internos e externos (Greenbaum et al., 2001).

Assim sendo, ainda no auge da etapa de seqüenciamento de genomas, começaram a surgir novas plataformas de pesquisa que possibilitam posicionar as funções individuais dos genes e seus produtos (RNAs e proteínas) dentro de um contexto global, dando início a um novo campo de estudos, denominado Genômica Funcional, cujas técnicas analíticas permitem avaliar os padrões de expressão gênica e protéica nas células e tecidos, pré-requisito básico para se entender como estas macromoléculas interagem de maneira dinâmica para produzir organismos complexos, capazes de se adaptar às influências do meio ambiente e a situações fisiológico-metabólicas específicas.

Os avanços teóricos e tecnológicos em nanobiotecnologia, robótica, genética, matemática e biologia computacional, entre outros, foram os fatores determinantes que permitiram e facilitaram os grandes avanços que ocorreram nessa área.

Os resultados das pesquisas em Genômica Funcional, notadamente daquelas que envolvem indivíduos geneticamente diferentes ou submetidos a condições contrastantes, têm permitido um entendimento mais rápido e preciso das relações gene-fenótipo, bem como dissecar as interações genótipo-ambientais que ocasionam mudanças significativas no fenótipo dos indivíduos. Em decorrência dessa nova abordagem científica, na qual ambos, genótipo e fenótipo, são tratados dentro de uma dimensão holística, surgem novas áreas de estudo, dentre as quais a Genômica Nutricional.

\section{Genômica}

Genômica é área da ciência que se dedica ao seqüenciamento dos nucleotídeos, mapeamento e

${ }^{\circledR} 2007$ Sociedade Brasileira de Zootecnia análise de genomas, os quais são constituídos por todo o DNA existente nas células de um indivíduo, inclusive os seus genes estruturais, seqüências regulatórias e regiões não codificantes.

A história do seqüenciamento teve início em 1977 quando Frederich Sanger e seus colaboradores descreveram uma metodologia para se determinar a ordem seqüencial dos nucleotídeos que compõe a estrutura do DNA, baseada no princípio da terminação controlada da replicação por didesoxinucleotídeos (Sanger et al., 1977).

Porém, na sua versão original, este método não era uma ferramenta adequada para o seqüenciamento de genomas complexos, da ordem de milhares, milhões, ou mesmo bilhões de pares de bases, como é o caso de organismos complexos (mamíferos, por exemplo). Tampouco havia disponibilidade de programas computacionais para analisar as seqüências geradas e ordená-las corretamente (processo chamado montagem do genoma), de forma a reconstituir a disposição exata que os genes e demais componentes do genoma ocupam no cromossomo.

De maneira que a genômica teve seu início somente no final da década de 80 , após o método de Sanger ter sido modificado para permitir o seqüenciamento de forma automatizada e integrada a um sistema de leitura computadorizado (Venter et al., 2001), possibilitando que este processo fosse realizado em plataforma de larga escala e alta performance.

Um dos fatores que mais contribuiu para o rápido desenvolvimento da genômica foi, sem a menor sombra de dúvida, o Projeto Genoma Humano. Considerado um dos projetos científicos mais ousados da história, começou a ser elaborado em 1984 e foi desenvolvido nos anos subseqüentes por um consórcio de cientistas dos Estados Unidos, Reino Unido, Japão, França, Alemanha e China, com o apoio financeiro de seus respectivos governos (Lander et al., 2001).

Dada sua magnitude científica e porte econômico, o Projeto Genoma Humano foi o fator determinante para proliferação de um setor industrial voltado à criação e aperfeiçoamento de produtos e equipamentos utilizados em pesquisas dessa natureza. As tecnologias desenvolvidas por esse setor foram fundamentais para o aumento da eficiência e redução dos custos do processo de seqüenciamento. 
A entrada do Brasil na chamada era genômica se deu somente em 1997, quando a FAPESP, com o intuito de gerar competência científica nesta área emergente, criou o Programa Genoma e tomou a iniciativa de organizar a Rede ONSA (Organization for Nucleotide Sequencing and Analysis), um consórcio de laboratórios ligados a diferentes instituições de pesquisa do Estado de São Paulo, estruturado para funcionar como um instituto virtual.

Desde que foi instituído, o Programa Genoma - FAPESP tem destinado expressivo volume de recursos financeiros, não apenas para a realização de diversos projetos de seqüenciamento, mas também para a concessão de bolsas de estudo que viabilizam o treinamento e aperfeiçoamento de estudantes, técnicos e pesquisadores. Tais investimentos têm resultado na capacitação de um contingente considerável de pesquisadores na área de genômica, cuja produção científica, de altíssima qualidade, tem dado grande visibilidade ao Brasil no cenário internacional.

Seguindo o modelo bem-sucedido da FAPESP, em dezembro de 2000 o Ministério da Ciência e Tecnologia, por intermédio do Conselho Nacional de Desenvolvimento Científico e Tecnológico (CNPq), lançou o Projeto Genoma Brasileiro e criou a Rede Nacional de Seqüenciamento, ampliando a expertise na área de Genômica em nível nacional.

Impulsionada pela redução dos custos do seqüenciamento e pela maior facilidade de acesso a essa tecnologia, a expansão da genômica em meados de 2000 foi um fenômeno que ocorreu a nível mundial, resultando no crescimento significativo do número de espécies a terem seu genoma seqüenciado.

Como pode ser observado na Tabela 1 , existem atualmente 1.470 projetos de seqüenciamento de grande porte cadastrados no NCBI (National Center for Biotechnology Information), cada um deles dedicado a uma espécie diferente.

Tabela 1 - Estatística dos Projetos de Seqüenciamento de Genomas.

\begin{tabular}{|c|c|c|c|c|}
\hline \multirow[t]{2}{*}{ Organismo } & \multicolumn{3}{|c|}{ Estatus } & \multirow[t]{2}{*}{ Total } \\
\hline & Completo & Montando & Em andamento & \\
\hline Procariotos & 487 & 335 & 387 & 1209 \\
\hline Arqueobactérias & 38 & 6 & 27 & 71 \\
\hline Bactérias & 449 & 329 & 360 & 1138 \\
\hline Eucariotos & 26 & 99 & 136 & 261 \\
\hline Animais & 4 & 42 & 53 & 99 \\
\hline Mamíferos & 2 & 16 & 14 & 32 \\
\hline Aves & & 1 & 1 & 2 \\
\hline Peixes & & 3 & 3 & 6 \\
\hline Insetos & 1 & 15 & 17 & 33 \\
\hline Vermes achatados & & 1 & 3 & 4 \\
\hline Vermes redondos & 1 & 2 & 3 & 6 \\
\hline Anfíbios & & & 1 & 1 \\
\hline Répteis & & & 2 & 2 \\
\hline Outros animais & & 5 & 12 & 17 \\
\hline Plantas & 5 & 2 & 37 & 44 \\
\hline Plantas superiores & 2 & 2 & 27 & 31 \\
\hline Algas verdes & 3 & & 9 & 12 \\
\hline Fungos & 10 & 38 & 20 & 68 \\
\hline Ascomicetos & 8 & 32 & 14 & 54 \\
\hline Basidiomicetos & 1 & 4 & 5 & 10 \\
\hline Outros fungos & 1 & 2 & 1 & 4 \\
\hline Protistas & 7 & 15 & 25 & 47 \\
\hline Apicomplexos & 1 & 7 & 7 & 15 \\
\hline Kinetoplastideos & 1 & 2 & 6 & 9 \\
\hline Outros protistas & 5 & 6 & 11 & 22 \\
\hline Total & 513 & 434 & 523 & 1470 \\
\hline
\end{tabular}

Fonte: NCBI 27/04/2007 (http://www.ncbi.nlm.nih.gov/genomes/static/gpstat.html) 
Os procariotos, organismos com genomas mais simples e de menor tamanho, constituem-se no grupo que tem maior número de projetos de seqüenciamento. Já em relação aos eucariotos, a maioria dos projetos está focada nas espécies do reino animal, predominantemente naquelas que pertencem ao grupo dos mamíferos e dos insetos, nos quais se encontram as espécies de interesse zootécnico (Tabela 2).

Em virtude da dimensão internacional e da grande abrangência científica, o Projeto Genoma Bovino é aquele que tem tido mais destaque dentre os projetos conduzidos com animais domésticos. Orçado em cinqüenta e três milhões de dólares, o projeto de seqüenciamento e anotação do genoma bovino, é coordenado pelo Baylor College of Medicine (Texas, USA) e conta com a participação de diversas instituições internacionais, inclusive do Brasil.

Os dados gerados no Projeto Genoma Bovino deverão ser utilizados tanto para propósitos da produção animal, quanto para os da saúde humana, haja vista que os cromossomos das duas espécies apresentam grande sintenia e que estes animais são usados como modelo de estudo para diversos aspectos da fisiologia e também de algumas das patologias humanas (Hocquette et al., 2007).

A última versão da montagem do genoma bovino (Btau 3.1) pode ser acessada livremente no endereço http://www.ncbi.nlm.nih.gov/genome /guide/cow/, no qual também são encontrados links para diversos bancos de dados públicos que contêm informações sobre o assunto.
Outra abordagem bastante utilizada em genômica, particularmente em estudos com eucariotos, é o seqüenciamento das Etiquetas de Seqüências Expressas ou ESTs (do inglês Expressed Sequence Tags), cujo objetivo é caracterizar a expressão temporal e local dos genes estruturais mediante a identificação de seus respectivos RNAs mensageiros.

Devido a grande instabilidade das moléculas de RNA, a estratégia utilizada nessa modalidade de seqüenciamento é a utilização do princípio da transcrição reversa para converter o RNA mensageiro em seu DNA complementar (cDNA), que posteriormente terá as extremidades seqüenciadas. Essas pequenas seqüências são então analisadas por programas computacionais (ferramentas de bioinformática) que têm a capacidade de identificar o gene que lhes deu origem.

As coleções de ESTs são muito importantes para os estudos de genômica funcional e têm sido largamente utilizadas para identificação de novos genes, mapeamento e anotação de transcritos (Smith et al., 2001), assim como para a construção de mapas comparativos, utilizando informações geradas em projetos conduzidos com outras espécies (Liu et al., 2004). Além disso, as bibliotecas de cDNA produzidas nestes projetos fornecem o substrato para a confecção das lâminas de microarrays utilizadas nos ensaios de expressão gênica (Suchyta et al., 2003).

Até o momento (Maio de 2007), já foram depositadas mais de 1.300.000 ESTs da espécie bovina no GenBank (http://www.ncbi.nlm.nih.

Tabela 2 - Projetos de seqüenciamento de animais domésticos.

\begin{tabular}{|c|c|c|c|c|}
\hline Organismo & $\begin{array}{l}\text { Tamanho do } \\
\text { genoma }(\mathrm{Mb})\end{array}$ & Estatus C & Cobertura & Grupo responsável \\
\hline Apis mellifera & 200 & Montado & $8 X$ & Baylor College of Medicine \\
\hline Bombis mori & 530 & Montado & $6 \mathrm{X}$ & Southwest Agricutural University, China \\
\hline Bos Taurus & 3000 & Montado & $6 \mathbf{X}$ & $\begin{array}{l}\text { Cattle Genome Sequencing International } \\
\text { Consortium }\end{array}$ \\
\hline Canis familiaris & 2400 & Montado & $1,5 \mathrm{X}$ & TIGR \\
\hline Canis familiaris & 2400 & Montado & $7,6 \mathrm{X}$ & Dog Genome Sequencing Consortium \\
\hline Equus caballus & - & Montado & $6,8 \mathrm{X}$ & Broad Institute \\
\hline Felis catus & 3000 & Montado & $2 \mathrm{X}$ & $\begin{array}{l}\text { The Genome Sequencing Platform, } \\
\text { The Genome Assembly Team }\end{array}$ \\
\hline Gallus gallus & 1200 & Montado & $6,6 \mathrm{X}$ & $\begin{array}{l}\text { International Chichen Genome } \\
\text { Consortium }\end{array}$ \\
\hline Oryctolagus cuniculus & 3500 & \multicolumn{2}{|c|}{ Em andamento } & NISC-NIH Intramural Sequencing Center \\
\hline Ovis aries & $\mathrm{E}$ & \multicolumn{2}{|c|}{ Em andamento } & International Sheep Genomics Consortium \\
\hline Sus scrofa & 2800 & \multicolumn{2}{|c|}{ Em andamento } & Swine Genome Sequencing Projetc (SGSP) \\
\hline
\end{tabular}

Fonte: NCBI 27/04/2007 (http://www.ncbi.nlm.nih.gov/genomes/leuks.cgi)

๑) 2007 Sociedade Brasileira de Zootecnia 
gov/Genbank/), a maior parte das quais procedentes de projetos desenvolvidos nos Estados Unidos. De maneira que os bovinos ocupam a quarta colocação entre os organismos que possuem maior número de ESTs seqüenciadas.

O Brasil também deu sua contribuição para a produção dessas coleções de ESTs. Financiado conjuntamente pela FAPESP e Central Bela Vista (http://www.centralbelavista.com.br/), o Projeto Genoma Bovino gerou um banco de dados que contém mais de 60.000 seqüências expressas exclusivamente em animais da subespécie Bos indicus. Além disso, durante seu desenvolvimento foram produzidas 18 bibliotecas de cDNA, algumas das quais tecido-específica, que se constituem num importante recurso para a confecção de lâminas de microarrays para estudos de expressão gênica com zebuínos.

Uma aplicação imediata dos resultados obtidos nestes projetos de seqüenciamento tem sido a construção de mapas genéticos saturados para identificação de marcadores para características quantitativas.

A grande quantidade de SNPs (single nucleotide polymorphisms) identificada nos bancos de dados desses projetos está sendo utilizada para saturar os mapas de QTLs (quantitative trait loci) existentes, com o intuito de identificar os genes responsáveis pelas variações fenotípicas em bovinos (Sonstegard \& Van Tassel, 2004). Esta estratégia tem gerado um grande número de marcadores moleculares que estão sendo usados para rastrear os animais portadores de alelos ou combinação de alelos que aumentam a produção.

Alguns marcadores, cujos testes empregam tecnologias mais simples, já estão sendo comercializados ao nível de criador (Tabela 3). Contudo, os métodos de genotipagem em larga escala, que fazem a análise simultânea de milhares de SNPs, ainda estão restritos ao campo da pesquisa.

É preciso salientar que a avaliação da eficácia desses marcadores no melhoramento genético ainda se encontra em fase preliminar e, portanto, deve ser considerada com cautela. Uma fonte confiável de informações sobre a validação de alguns testes comerciais pode ser encontrada na página web do National Beef Cattle Evaluation Consortium (http://www.nbcec.org/nbcec/index. html).

\section{Genômica funcional}

Genômica funcional é a vertente da genômica cujo foco está voltado para a elucidação das funções que cada gene exerce no organismo e, ao mesmo tempo, como esses genes interagem entre si dentro

Tabela 3 - Testes comerciais para a genotipagem de marcadores moleculares em bovinos (modificado de Hocquette et al., 2007).

\begin{tabular}{|c|c|c|c|c|}
\hline Gene & Características & Ano & Procedência & Comercializador \\
\hline TG & Marmoreio & 2000 & CSIRO/MLA & Genetic Solutions P/L \\
\hline CAST & Maciez da carne & 2002 & CSIRO/MLA/ & \\
\hline & & & Beef CRC & Genetic Solutions P/L \\
\hline CAPN1 & Maciez da carne & 2003 & USDA/AgResearch NZ & \\
\hline DGAT1 & $\begin{array}{l}\text { Produção de gordura } \\
\text { no leite }\end{array}$ & 2003 & $\begin{array}{l}\text { Univ. de Lieve/ } \\
\text { Tech Uni Muench }\end{array}$ & Merial \\
\hline GH1 & Marmoreio & 2003 & NIAS, Japão & $\begin{array}{l}\text { Prescribe Genomics } \\
\mathrm{CO}\end{array}$ \\
\hline LEP & Marmoreio/Gordura & 2003 & Univ. de & \\
\hline Múltiplos testes & Maciez da carne & $2003 / 04$ & Saskatchewan & $\begin{array}{l}\text { Merial } \\
\text { Genetic Solutions P/L }\end{array}$ \\
\hline GHR & Produção de leite & 2004 & Univ. de Lieve & Merial \\
\hline SCD & Relação de ácidos graxos & 2004 & Univ. Kobe & $\begin{array}{l}\text { Prescribe Genomics } \\
\mathrm{CO}\end{array}$ \\
\hline Múltiplos testes & Marmoreio & 2004 & & Genetic Solutions P/L \\
\hline Múltiplos testes & $\begin{array}{l}\text { Várias características } \\
\text { para gado de leite }\end{array}$ & $2004 / 05$ & & Merial \\
\hline CAPN3 & Maciez da carne & 2006 & $\begin{array}{l}\text { CSIRO/MLA/ } \\
\text { Beef CRC }\end{array}$ & Genetic Solutions P/L \\
\hline Múltiplos testes & Eficiência alimentar & 2006 & $\begin{array}{l}\text { CSIRO/MLA/ } \\
\text { Beef CRC }\end{array}$ & Genetic Solutions P/L \\
\hline
\end{tabular}

() 2007 Sociedade Brasileira de Zootecnia 
das redes biológicas que controlam as características fenotípicas (Mutch et al., 2005). As duas abordagens mais utilizadas nesse campo de estudo têm sido a análise do perfil global da expressão gênica (transcriptoma) e a análise sistemática das proteínas (proteoma).

Dentre as metodologias utilizadas nos estudos do transcriptoma, a mais difundida é a análise da expressão gênica por microarrays, uma vez que permite a avaliação simultânea da expressão de milhares de genes em diferentes tecidos, provenientes de indivíduos que foram submetidos a condições contrastantes ou que se encontram em diferentes estágios do desenvolvimento (Schena et al., 1995).

Esta técnica é baseada no uso de um chip de DNA, que nada mais é do que uma plataforma sólida, cuja superfície contém um grande número de genes distribuídos de forma ordenada. Embora existam variações, o tipo mais comum é aquele em que a matriz sólida é uma lâmina de vidro usada em microscopia (também chamada de slide), contendo milhares de spots (locais onde se encontram os genes), nos quais está depositada uma quantidade infinitamente pequena de DNA (sonda). As fontes de DNA mais comumente utilizadas como sondas são os produtos de PCR amplificados de cDNAs ou oligonucleotideos sintetizados a partir de seqüências depositadas no GenBank.

O fundamento dessa tecnologia é a utilização de um slide no qual as sondas foram imobilizadas em quantidades e posições precisamente definidas, para se fazer a hibridização com um pool de RNAs mensageiros extraídos de amostras biológicas, previamente marcados com fluoróforos (marcadores florescentes), também chamados de alvos ou targets. Após o processo de hibridização o slide é lavado para remoção do targets excedentes (que não se ligaram à sonda) e, em seguida, exposto a raios laser para excitar os fluoróforos, fazendo com estes emitam luz (fluorescência).

Em princípio, quanto maior a expressão de um determinado gene, maior será a quantidade de targets marcados com o fluoróforo e, consequentemente, maior será a intensidade da fluorescêcia do complexo target-sonda após a hibridização (Hiendleder et al., 2005).

Devido ao seu caráter prospectivo, e pela facilidade em identificar genes diferencialmente expressos, as análises de microarrays têm sido

๑ 2007 Sociedade Brasileira de Zootecnia extensivamente utilizadas nas áreas médica e farmacológica, visando à identificação de conjuntos de genes associados à pré-disposição e ao desenvolvimento de doenças, elaboração de sistemas de diagnóstico, e na identificação de produtos com potencial terapêutico (drogas e novos alvos para medicamentos).

Tendo em vista a complexidade dos fatores envolvidos nas respostas aos estados patológicos e na determinação das características produtivas nos animais domésticos, a utilização da tecnologia de microarrays tem despertado grande interesse por parte dos setores ligados à produção animal, pois ela permite a caracterização dos status sanitário, fisiológico e nutricional de acordo com a raça, tipo genético, manejo aplicado ou mesmo o ambiente de criação desses animais.

De fato, a disponibilidade de chips de DNA para os estudos de expressão gênica em animais tem aumentado significativamente nos últimos anos e, atualmente, existem chips específicos para diversas espécies de interesse zootécnico, inclusive a bovina (Tabela 4).

No âmbito da nutrição, a análise do transcriptoma é uma ferramenta extremamente útil para se investigar quais e de que maneira os genes são afetados pelos nutrientes essenciais e não essenciais, evidenciar novos mecanismos de ação e novas funções para os nutrientes, investigar possíveis efeitos colaterais provocados por componentes da dieta, determinar como as variações (diferenças individuais, estágio do crescimento ou do desenvolvimento, efeitos ambientais, etc...) alteram as necessidades ou as respostas do organismo a um dado nutriente ou dieta, investigar quais as conseqüências dos desbalanços nutricionais provocados pela inadequação das dietas, sem contar outras abordagens genéticas e evolucionárias relativas à nutrição (German \& Young, 2004).

Embora o volume de publicações sobre o assunto ainda não seja expressivo, a tecnologia de microarrays já esta sendo utilizada nos estudos de nutrição dos ruminantes, notadamente naqueles delineados para avaliar os efeitos do nível nutricional da dieta (Lehnert et al., 2006 ; Loor et al., 2007).

Apesar da crescente popularidade na aplicação desta tecnologia, é necessário ressaltar que a formação do RNA mensageiro é apenas o primeiro passo de uma longa seqüência de eventos que 
Tabela 4 - Alguns exemplos de arrays disponíveis para estudos de expressão gênica em bovino (modificado de Hocquette et al., 2007).

\begin{tabular}{|c|c|c|c|}
\hline Array & Tipo & Procedência & Detalhes \\
\hline MEM array & cDNA & França $^{(1)}$ & $\begin{array}{l}1896 \text { cDNAs oriundos de músculo, } \\
\text { glândula mamária e embrião }\end{array}$ \\
\hline NBFGC Microarray & cDNA & $\begin{array}{l}\text { Universidade Estadual } \\
\text { de } \text { Michigan }^{(2)}\end{array}$ & $\begin{array}{l}>18000 \text { transcritos de bibliotecas de } \\
\text { vários tecidos (MARC 1-4) }\end{array}$ \\
\hline Bovi Analyzer & cDNA & $\begin{array}{c}\text { Universidade Estadual } \\
\text { de Iowa }\end{array}$ & 10608 cDNAs de Bibliotecas MARC \\
\hline $\begin{array}{l}\text { Beef CRC muscle } \\
\text { and fat array }\end{array}$ & cDNA & $\begin{array}{l}\text { CSIRO e Beef CRC, } \\
\text { Austrália } \\
\end{array}$ & $\begin{array}{l}>9000 \text { sondas oriundas de bibliotecas de } \\
\text { cDNAs de músculo esquelético tecido } \\
\text { adiposo }\end{array}$ \\
\hline $\begin{array}{l}\text { Bos taurus } \\
\text { (bovine) OpArray }\end{array}$ & $\begin{array}{l}\text { Oligos } \\
\text { longos }\end{array}$ & $\begin{array}{l}\text { Operon } \\
\text { Biotechnologies }^{(5)}\end{array}$ & $\begin{array}{l}8329 \text { longos oligos de transcritos (EST) } \\
\text { bovinos }\end{array}$ \\
\hline Gene Chip & $\begin{array}{l}\text { Pequenos Oligos } \\
\text { sintetizados in situ }\end{array}$ & Affymetrix $^{(6)}$ & $\begin{array}{l}23000 \text { sondas representando genes } \\
\text { contidos no GenBank }\end{array}$ \\
\hline $\begin{array}{l}\text { Bovine whole } \\
\text { genome long } \\
\text { oligonucleotídeo } \\
\text { expression array }\end{array}$ & $\begin{array}{l}\text { Oligos } \\
\text { longos }\end{array}$ & $\begin{array}{l}\text { Consórcio de } \\
\text { microarray bovino, } \\
\mathrm{USA}^{(7)}\end{array}$ & $\begin{array}{l}\text { > } 2005 \text { genes oriundos de um banco de } \\
\text { dados de EST }\end{array}$ \\
\hline $\begin{array}{l}\text { Bos taurus e } \\
\text { de Array distintos }\end{array}$ & $\begin{array}{l}\text { Oligos } \\
\text { longos }\end{array}$ & Agilent $^{(8)}$ & $\begin{array}{l}21475 \text { sondas representando } 19500 \text { genes } \\
\text { bovinos }\end{array}$ \\
\hline
\end{tabular}

(1) = Bernard et al. (2005); (2) Suchyura et al. (2003); (3) = www.ans.iastate.edu/report/air/2004pdf/ AS1877,pdf; (4) = Lehert et al. (2004); (5) = www.operon.com; (6) = www.affymetrix.com; (7) = Elsik et al. (2006); (8) = earrat.chem.agilent.com/earray.

resultam na síntese das proteínas funcionais, que são, em última instância, as moléculas responsáveis pelo fenótipo das células.

Logo após a transcrição do DNA, o RNA resultante está sujeito a modificações (processamento alternativo, edição do RNA mensageiro e poliadenilação) que podem resultar na formação de diferentes isoformas de proteínas, geradas a partir de um único gene (Newman, 1998). Além disso, os mecanismos que regulam o processo de tradução, as modificações pós-traducionais e, principalmente, o processo de proteólise celular, são fatores que afetam significativamente as quantidades e as características estruturais e funcionais das proteínas (Graves \& Haystead, 2002). Neste sentido, diversos trabalhos têm demonstrado que o conteúdo de proteínas na célula não é um reflexo direto da abundancia dos RNAs mensageiros específicos (Gygi et al., 1999, Chen et al., 2002).

Assim sendo, as tecnologias que permitem a caracterização do perfil global das proteínas presentes numa célula, tecido, ou organismo, como o são a eletroforese bi-dimensional e a espectrometria de massa, tornam-se ferramentas poderosas para comparar diferentes estados de um sistema biológico, como por exemplo, entre sistemas normais e doentes, resistentes e susceptíveis ou ainda com características fenotípicas positivas e negativas.

Em virtude da complexidade das misturas protéicas que são analisadas em estudos do proteoma, primeiramente é necessário separá-las para, posteriormente, fazer a identificação de cada proteína individualmente.

Uma das tecnologias mais utilizadas para separação de proteínas em misturas complexas é a eletroforese bi-dimensional em géis de poliacrilamida ou simplesmente 2D-PAGE (Wang \& Hanash, 2005).

Seu princípio é baseado na condução da eletroforese em duas etapas, com critérios diferentes de separação. Na chamada primeira dimensão,

๑๐ 2007 Sociedade Brasileira de Zootecnia 
as proteínas são separadas pelo ponto isoelétrico em gradiente de $\mathrm{pH}$ e, em seguida (segunda dimensão), separadas de acordo com o peso molecular. Nos passos subseqüentes o gel é corado, para a visualização do padrão de migração de cada proteína (spot), sendo em seguida digitalizado para que sua imagem possa ser analisada. De maneira que as diferenças quantitativas e qualitativas no perfil de proteínas da amostra se refletem em alterações quantitativas e qualitativas no padrão de migração na eletroforese, as quais podem ser detectadas na análise das imagens (Hiendleder et al., 2005).

Para a identificação das proteínas que se encontram diferencialmente representadas na amostra, basta remover seu spot do gel e analisálo por espectrometria de massa ou fazer o seqüenciamento da porção $\mathrm{N}$-terminal pelo método de degradação de Edman.

As técnicas para o estudo do proteoma ainda não se popularizaram com a mesma magnitude que as técnicas utilizadas no estudo do transcriptoma, tampouco suas metodologias estão devidamente padronizadas para permitir a comparação entre resultados que foram obtidos em experimentos diferentes, porém conduzidos de forma similar. Contudo, a tendência é de que haja um aumento gradativo na sua utilização, inclusive na área zootécnica.

A aplicação conjunta das tecnologias empregadas em estudos de transcriptoma (microarrays) e proteoma (eletroforese bi-dimensional e espectrometria de massa) em ensaios que envolvem indivíduos geneticamente diferentes, ou submetidos a condições ambientais contrastantes, permite um entendimento mais rápido e preciso das relações gene-fenótipo, e possibilita dissecar as interações genótipo-ambientais que ocasionam mudanças significativas no fenótipo destes indivíduos. A utilização de ferramentas de bioinformática adequadas para uma análise integrada dos dados do genoma, transcriptoma e proteoma é um ponto crucial para a obtenção de resultados confiáveis (Bailey, 1999).

\section{Genômica nutricional}

Genômica nutricional é o novo campo da nutrição que emerge na era pós-genômica com o objetivo de elucidar a complexa interação existente entre a dieta e o genoma dos indivíduos, mediante utilização de tecnologias desenvolvidas para análise do transcriptoma e do proteoma (Mutch $e t$ al., 2005).

Definida como a interface entre o ambiente nutricional e os processos genético-celulares, a Genômica Nutricional dedica-se ao estudo das interações entre os componentes químicos das dietas (nutrientes) e o material genético dos indivíduos (genótipo), ou seja, dos mecanismos moleculares envolvidos na interação nutrientesgenótipo e a maneira como estas afetam o fenótipo (Kaput \& Rodriguez, 2004).

Dentro de seu escopo existem duas vertentes distintas: a Nutrigenômica, voltada para o entendimento dos efeitos dos nutrientes sobre os mecanismos envolvidos na expressão gênica e a Nutrigenética, que estuda os efeitos das variações nas sequiências do DNA (polimorfismos) sobre o aproveitamento dos nutrientes e/ou o desenvolvimento de doenças metabólicas.

Os efeitos dos componentes químicos da dieta sobre a expressão gênica podem ser diretos ou indiretos, dependendo do papel que estes desempenham dentro das células. Neste sentido, os nutrientes podem:

1) atuar como ligantes para receptores de fatores de transcrição;

2) serem metabolizados por rotas metabólicas primárias ou secundárias, alterando desse modo as concentrações de substratos ou intermediários;

3) influir positiva ou negativamente nas vias de sinalização celular (Kaput \& Rodriguez, 2004).

Uma das classes de nutrientes que afetam a expressão gênica é a dos ácidos graxos polinsaturados de cadeia longa ou LC-PUFA. Vários estudos de expressão gênica por microarrays têm evidenciado os efeitos destes compostos sobre diversos processos fisiológicos, dentre os quais o crescimento, desenvolvimento neurológico, ganho de massa muscular ou de gordura, reprodução, sistema imune inato e adquirido, sem contar que também estão relacionados com praticamente todas as doenças crônicas e degenerativas que acometem os seres humanos.

Seu efeito sobre a expressão gênica nesta grande amplitude de processos está relacionado com o fato de eles atuarem como ligantes para um 
número significativo de fatores de transcrição, que atuam em vários tecidos do organismo. De maneira que os LC-PUFA constituem-se numa classe de nutrientes ideal para estudos de nutrigenômica (Mutch et al., 2005)

Além disso, esses ácidos graxos estão relacionados com a modulação da atividade de proteínas e participam ativamente do metabolismo dos lipídeos, fatos que concorrem para explicar a multiplicidade de ações.

A influência dos nutrientes sobre a estabilidade do genoma é outra questão importante que tem sido abordada em nutrigenômica. O estatus nutricional durante a fase de desenvolvimento fetal pode alterar o estado epigenético do genoma, afetando os níveis da expressão gênica durante toda a vida pós-natal (Stover, 2004).

Os efeitos das alterações epigenéticas não estão relacionados com mudanças na seqüência primária do DNA, mas sim com os mecanismos que controlam a expressão gênica, como é o caso da metilação dos resíduos de citosina, sendo uma das explicações para as diferenças fenotípicas sutis que são observadas nos gêmeos monozigóticos ou nos indivíduos clonados.

O estabelecimento dos padrões de metilação ocorre na fase inicial do desenvolvimento e pode se propagar pela vida toda, criando uma situação peculiar, na qual características fenotípicas controladas em nível de genoma, não são passíveis de serem herdadas.

Um dos fatores que exerce grande influência no padrão de metilação é a disponibilidade celular das vitaminas que participam do metabolismo de um-carbono $\left(\mathrm{B}_{6}, \mathrm{~B}_{12}\right.$ e ácido fólico), uma vez que o grupo metil utilizado no processo de metilação do DNA é originário dessa via metabólica.

Por outro lado, variações genéticas dentro de uma mesma população fazem com que os indivíduos respondam de forma diferente a uma mesma dieta. É o caso dos portadores de galactosemia ou de fenilcetonuria, duas doenças causadas por defeito genético em um único gene, que necessitam dietas isentas de lactose ou de fenilalanina para poderem ter uma vida normal.

Este é um exemplo cuja característica fenotípica é controlada por um único gene. Entretanto, existe considerável evidência de que doenças crônicas, decorrentes de anomalias poligênicas, possam estar associadas à dieta. Hipercoles- terolemia, aterosclerose, diabete tipo 2, obesidade e diversos tipos de câncer, são exemplos clássicos.

A diabete tipo 2 é um modelo de estudo interessante, pois os genes regulados pela dieta tem um papel central no seu desenvolvimento. Quando diagnosticados com essa doença, alguns indivíduos conseguem controlar os seus sintomas apenas com o aumento da atividade física e redução na ingestão de calorias, ou seja, controlam a expressão da informação genômica pela mudança em variáveis ambientais (a dieta). Já outros indivíduos são totalmente refratários a esse tipo de controle e precisam ser tratados com medicamentos (Marti et al., 2005). De maneira que a identificação de alelos que contribuem para o desenvolvimento das doenças crônicas, de caráter poligênico, é um dos campos que têm recebido mais atenção dentro da genômica nutricional humana.

Assim sendo, verifica-se que as interações entre os nutrientes e o genoma dos indivíduos ocorrem em diferentes etapas do processo de expressão gênica, afetando tanto o transcriptoma, quanto o proteoma. No entanto, seus efeitos podem ser monitorados e analisados pelas ferramentas de genômica funcional atualmente disponíveis (Figura 1).

O genoma de uma espécie e as variações genéticas que existem entre os indivíduos dessa espécie são resultantes da adaptação às pressões evolucionárias a que ela foi submetida. Durante esse processo, a nutrição talvez seja a variável ambiental mais persistente e, portanto, uma das que mais contribui para moldar um genoma e suas variações (Stover, 2004).

Assim, considerando as diferenças que existem entre os indivíduos de uma mesma espécie, é plausível pensar que cada um possa reagir de forma diferente ao ser alimentado com a mesma dieta e, com o uso das ferramentas de genômica, está sendo possível identificar e entender as bases genéticas dessas diferenças, bem como analisá-las dentro de um contexto populacional.

Os estudos de genômica nutricional na área animal ainda são incipientes, mas os exemplos tomados da área humana deixam claro que eles serão de grande valia, notadamente para o aperfeiçoamento e evolução das normas e padrões de alimentação das diferentes espécies. De maneira que ela deverá redirecionar a nutrição animal para

๑ 2007 Sociedade Brasileira de Zootecnia 


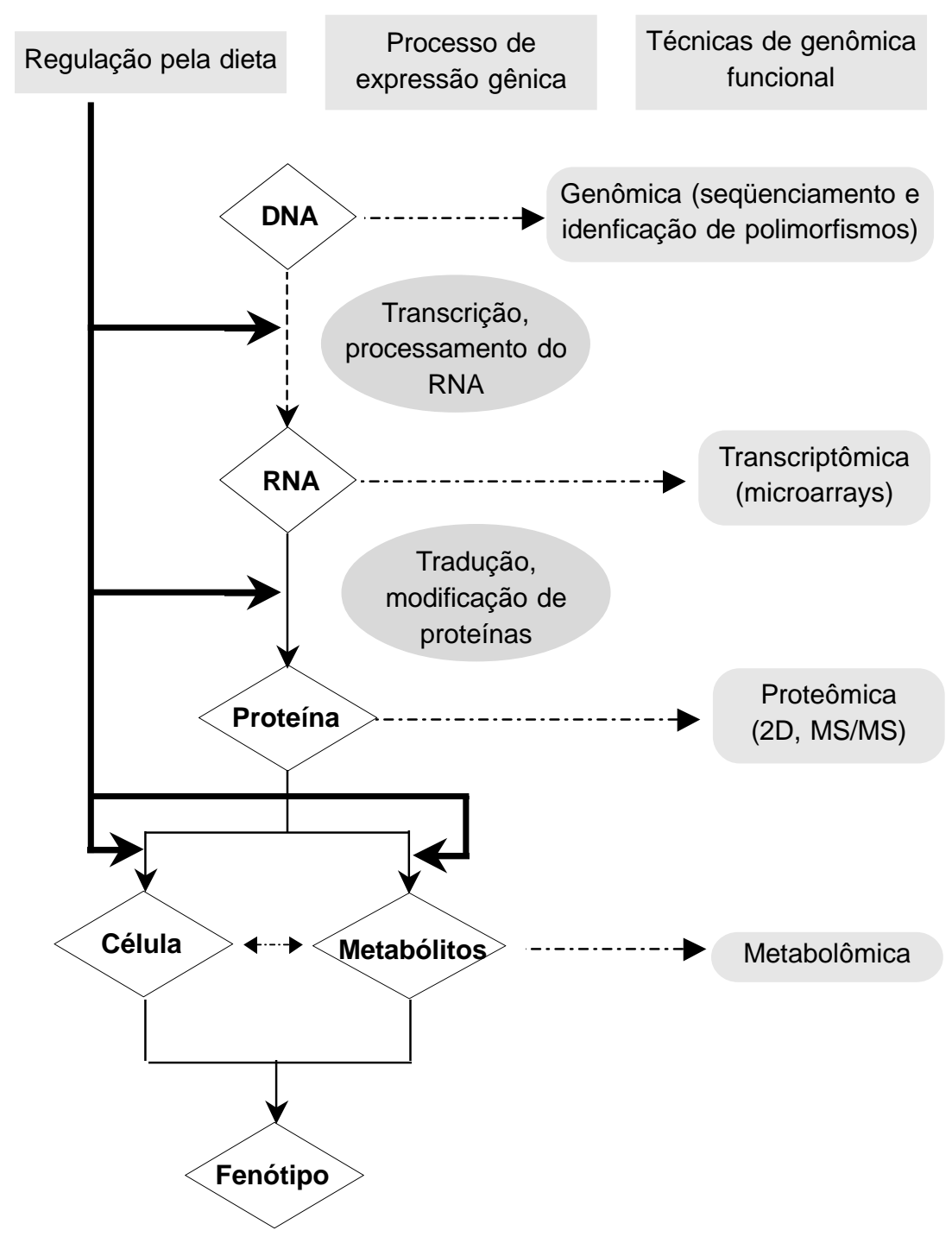

Figura 1 - Representação esquemática dos passos envolvidos na expressão gênica (centro), estágios nos quais a dieta pode modular estes processos (esquerda), e as técnicas de genômica funcional utilizadas para analisar cada estágio (direita). (Extraído e modificado de Elliot \& Ong, 2007).

uma abordagem mais personalizada, na qual as dietas das diferentes espécies serão adequadas em função da raça, linhagem, ou mesmo grupos de animais com características semelhantes.

\section{Literatura citada}

BAILEY, J.E. Lessons from metabolic engineering for functional genomics and drug discovery. Nat. Biotechnol., v.17, p.61618,1999

CHEN, G.; GHARIB, T.G.; HUANG, C.C. et al. Discordant protein and mRNA expression in lung adenocarcinomas. Mol. Cell. Proteomics, v.1, p.304-13, 2002.

ELLIOTT, R. \& ONG, T.J. Science, medicine, and the future Nutritional genomics. BMJ, v.324, p.1438-1442, 2007.

GERMAN, B. \& YOUNG, V. R. Nutrition and Genomics. Nestlé Nutrition Workshop Series Clinical \& Performance Program, v.9, p.243-263, 2004.

GRAVES, P.R. \& HAYSTEAD, T.A.J. Molecular biologist's guide to proteomics. Microbiol. Mol. Biol. Rev., v.66, p. 39-
63, 2002.

GREENBAUM, D.; LUSCOMB, N.M.; JANSEN, R. et al. Interrelating different types of genomic data, from proteome to secretome: 'Oming in on function. Genome Res., v.11, p. 1463-1468, 2001.

GYGI, S.P.; ROCHON, Y.; FRANZA, B.R. et al. Correlation between protein and mRNA abundance in yeast. Mol. Cell. Biol., v.19, p.1720-1730, 1999.

HIENDLEDER, S.; BAUERSACHS, S.; BOULESTEIX, A. et al. Functional genomics: tools for improving farm animal health and welfare. Rev. Sci. Tech. Off. Int. Epiz., v.24, n.1, p. 354-377, 2005.

HOCQUETTE, J.F.; LEHNERT, S.; BARENDSE, W. et al. Recent advances in cattle functional genomics and their application to beef quality. The International Journal of Animal Biosciences, v.1, p.159-173, 2007.

KAPUT, J. \& RODRIGUEZ, R.L. Nutritional genomics: the next frontier in the postgenomic era. Physiol. Genomics, v. 16, p.166-177, 2004.

LANDER, E.S.; LINTON, L.M.; BIRREN, B. et al. Initial sequencing and analysis of the human genome. Nature, v. 409, p. 860-921, 2001.

LEHNERT, S.A.; BYRNE, K.A.; REVERTE, A. et al. Gene

๑) 2007 Sociedade Brasileira de Zootecnia 
expression profiling of bovine skeletal muscle in response to and during recovery from chronic and severe undernutrition J. Anim Sci., v.84, p.3239-3250, 2006

LIU, L.; GONG, G.; LIU, Y. et al. Multi-species comparative mapping in silico using the COMPASS strategy. Bioinformatics, v.20, n.2, p.148-154, 2004.

LOOR, J.J.; DANN, H.M.; GURETZKY, N.A.J. et al. Plane of nutrition prepartum alters hepatic gene expression and function in dairy cows as assessed by longitudinal transcript and metabolic profiling. Physiol. Genomics, v.27, p.29-41, 2007.

MARTI, A.; MORENO-ALIAGA, M.A.J.; ZULET M.A.A. et al. Avances en nutrición molecular: nutrigenómica y/o nutrigenética. Nutr. Hosp., v.3, p.157-164, 2005.

MUTCH, D.M.; WAHLI, W.; WILLIAMSON, G. Nutrigenomics and nutrigenetics: the emerging faces of nutrition. FASEB J., v.19, p.1602-16, 2005.

NEWMAN, A. RNA splicing. Curr. Biol., v.8, p.R903R905,1998.

SANGER, F.; NICKLEN, S. \& COULSON, A.R. DNA sequencing with chain-terminating inhibitors. Proc. Nat. Acad. Sci., v.74, n.12, p.5463-5467, 1977.

SCHENA, M.; SHALON, D.; DAVIS, R.W. et al. Quantitative monitoring of gene expression patterns with a complementary DNA microarray. Science, v.270, n.5235, p.467-470, 1995. SMITH, T.P.L.; GROSSE, W.M.; FREKING, B.A. et al. Sequence evaluation of four pooled-tissue normalized bovine cDNA libraries and construction of a gene index for cattle. Genome Research, v.11, p.626-630, 2001.

SONSTEGARD, T.S. \& VAN TASSELL, C.P. Bovine genomics update: making a cow jump over the moon. Genet. Res., v.84, p.3-9, 2004.

STOVER, P.J. Nutritional genomics. Physiol. Genomics, v.16, p. 161-165, 2004.

SUCHYTA, S.P.; SIPKOVSKY, S.; KRUSKA, R. et al. Development and testing of a high-density cDNA microarray resource for cattle. Physiol. Genomics, v.15, p.158-164. 2003.

VENTER, J.C.; ADAMS, M.D.; MYERS, E.W. et al. The sequence of the human genome. Science, v.291, p.1304-1351, 2001.

WANG, H. \& HANASH, S. Intact-protein based sample preparation strategies for proteome analysis in combination with mass spectrometry. Mass. Spectrom. Rev., v.24, n.3, p. 413-426, 2005. 